\title{
EN DEFENSA DEL TERRITORIO: \\ LAS COALICIONES MILITARES \\ ANTIRROMANAS EN EL PIRINEO OCCIDENTAL (SIGLOS II-I A.C.)
}

\author{
Jokin Lanz ${ }^{1}$ \\ https://doi.org/10.18778/8220-421-6.13
}

\begin{abstract}
After the arrival of Rome in the western surroundings of the Pyrenees, some of the communities that inhabited the region quickly formed coalitions to defend their territory and were able to face the foreign power. For this purpose, strong mechanisms were used that were deeply rooted in the region and had proved to be capable of creating large military coalitions amongst different communities, giving them a certain military strength, and by adopting, when necessary, typically Roman military techniques. The attitude of some of these communities was clear evidence of the high degree of cohesion and ethnic consciousness that they had previously developed.
\end{abstract}

Keywords: Aquitanians, Celtiberians, Berones, Autrigones, alliance.

Palabras clave: Aquitanos, celtíberos, berones, autrigones, alianza.

1 UPNA y Fundación Arkeolan, C/Eskoleta 1, 20302 Irun (Gipuzkoa, España),jlanz@irun.org

Este trabajo fue realizado en el periodo de contratación como doctor reciente hasta la integración en programas de formación postdoctoral (Dokberri 2017) en el área de Historia Antigua del Departamento de Estudios Clásicos de la Facultad de Letras de la Universidad del País Vasco - Euskal Herriko Unibertsitatea. 


\section{Introducción}

A partir del análisis de las fuentes grecolatinas podemos observar que, con la llegada de los romanos, las distintas comunidades que habitaban a ambos lados del entorno circumpirenaico occidental adoptaron una actitud y unas medidas que distaban de ser homogéneas entre sí. Mientras algunos pueblos optaron por abrazar soluciones pacíficas expuestas por la potencia itálica, otros decidieron hacerle frente mediante las armas dando lugar a diversas contiendas bélicas cuyo desenlace fue siempre favorable para Roma. En dicho proceso, destacan las coaliciones militares antirromanas impulsadas por las comunidades locales, un fenómeno que apenas ha llamado la atención de los investigadores hasta hace escasos años y que nosotros procederemos a analizar para el caso concreto de la citada región ${ }^{2}$.

Las coaliciones militares se crean del compromiso de dos o más comunidades que deciden colaborar o apoyarse de manera recíproca, generalmente siguiendo el objetivo de hacer frente a un enemigo común con un potencial bélico superior, por lo menos en comparación con la del miembro más débil de la alianza. La primera noticia certera en torno a este tipo de tratados en el territorio nos lleva hasta el 188/187 a.C., fecha en la que un gran ejército celtíbero fue derrotado dos veces consecutivas por el pretor Lucio Manlio Acidinio, en la segunda ocasión cerca del oppidum de Calagurris (Calahorra, La Rioja), causando doce mil muertos y dos mil prisioneros -captivi- entre los derrotados ${ }^{3}$. Unos años más tarde, Tiberio Sempronio Graco, pretor de la Citerior, obligó a las comunidades celtíberas a que aceptaran unos acuerdos que

2 Véanse las referencias recogidas en las obras de García Riaza y Pérez Rubio en la bibliografía al final.

3 Liv. Per. 39.21. Livio emplea a lo largo de su obra los imprecisos términos de urbs y oppidum para referirse a Calagurris (Bedon, 2003: 243, nota 46). En opinión de Cantón, en este pasaje el término Celtiberi podría encubrir ciertas realidades étnicas menores del Valle Medio del Ebro (2003: 43). 
hicieron posible que imperase una relativa paz durante el siguiente cuarto de siglo. Así, tras vencer a un gran ejército celtíbero en las cercanías del Mons Chaunus (seguramente el Moncayo, Zaragoza-Soria), con el objetivo de celebrar el triunfo y siguiendo razones estratégicas de índole militar, en el 179 a.C. fundó sobre la indígena Ilurcis la civitas de Gracchurris (Alfaro, La Rioja) ${ }^{4}$.

La siguiente mención se enmarca dentro de las Guerras Sertorianas (81-72 a.C.), una de las contiendas civiles que azotaron la República romana en su último siglo de vida. En el año 77, el general Quinto Sertorio emprendió una campaña para castigar a las comunidades de los Autricones y Berones ${ }^{5}$, quienes habían hostigado en varias ocasiones a las fuerzas sertorianas mostrándose favorables a Pompeyo, pidiéndole ayuda y ofreciéndole guías 6 . Sin embargo, no se trataba únicamente de alianzas bilaterales realizadas por ambos pueblos con el general romano, ya que en el relato de Livio podemos apreciar que autrigones y berones estaban coaligados de alguna manera entre sí. El patavino señala que Sertorio avanzó por el valle del Ebro devastando los territorios de los Bursaoni ${ }^{7}$, Cascantini y Gracchurritani ${ }^{8}$, acampando cerca de la urbs aliada-socia- de Calagurris. Al día siguiente, Sertorio construyó un puente, cruzó el río Ebro y continuó hacia el territorio berón atravesando el ager Vasconum, no sabemos si hostigándolo, alcanzando cuando ya era de noche el objetivo principal

4 Liv. Per. 41; Fest. 7.68.5. Sobre dicha fundación, Peréx, 1986: 159; López Melero, 1987: 171 y 174-175; Hernández Vera, 2002: 177 y 179, García Riaza, 2005: 473-474.

5 Para los límites geográficos de los autrigones y berones: Emborujo, Ortiz de Urbina, Santos, 1992: 453-455; Fatás, 1992: 229; Labeaga, 1999-2000: 209-210; Collado, 2006: 105-106; Santos, 2006: 182-184 y 186.

6 Liv. Frag. 91.22.10.

7 Tradicionalmente identificado con Bursao (Borja, Zaragoza), concretamente con el yacimiento de Cueva de Esquilar o tal vez el Cerro de la Corona (García Mora, 1992: 208).

8 Los cascantini eran los antecesores de la civitas latina de Cascantum (Cascante, Navarra) y los gracchuritani eran los habitantes de Gracchurris, actual Alfaro (La Rioja). Véase Pérex Agorreta, 1986. 
de la expedición de castigo: la urbs berona de Vareia, la plaza más importante de la zona ${ }^{9}$. No obstante, según Livio, los vareienses estaban preparados y habían hecho llamar a equites de suae gentis (los berones) y de los autrigones para que los ayudasen ${ }^{10}$. El pasaje está mutilado y el relato de Livio termina aquí. Las fuentes escritas que narran los hechos nos han llegado en unas condiciones que impiden conocer al detalle las Guerras Sertorianas y menos aún su completo desarrollo en el entorno pirenaico occidental. No obstante, los hallazgos arqueológicos de los últimos años nos permiten reconstruir con algo más de exactitud el trayecto militar del general sabino por estos territorios y el desenlace de la batalla: la plaza fue destruida y abandonada seguramente por un ataque violento, por lo que suponemos que el general rebelde terminó esta parte de la expedición con éxito (Armendáriz, 2008:280-282; 2009: 332).

Es durante la Guerra de las Galias emprendida por César, concretamente en la conquista de Aquitania dirigida por su legado Publio Craso, hijo del triunviro, cuando se forja la mayor coalición conformada por las gentes del territorio. En el 56 a.C., Craso fue enviado con doce cohortes y un gran número de jinetes - magno numero equitatus- a someter a los aquitanos para así impedir que

9 Liv. Frag. 91.22.12. Vareia fue una civitas berona que la historiografía generalmente ha identificado con el yacimiento del barrio logroñés de Varea. Empero, en dicho yacimiento los restos más tempranos se adscriben a la época imperial, hecho que ha llevado a pensar que la ciudad prerromana se hallaba en otro lugar. Livio menciona que durante el conflicto sertoriano Vareia era la plaza más importante de la región, por eso numerosos arqueólogos la han situado al otro lado del Ebro, en el yacimiento de La Custodia, Viana (Navarra). La Custodia muestra síntomas de haber sido atacada y abandonada para siempre en algún momento del s. I a.C., legando un puñado de vicus y villae. Posiblemente la mayor parte de la población superviviente fuera trasladada a la Vareia romana, al otro lado del río (Espinosa Ruiz, 1990: 6-7; 1994a: 106-108; 1994b: 99-103; Álvarez Clavijo, Labeaga, Martínez Clemente, 1994: 65-69; Armendáriz, 1997-1998: 20-25; 2008: 11, 26-27, 265, 281 y 286-292; 2009: 330; 2013: 189; Labeaga, 1999-2000: 211-212).

10 Liv. Frag. 91.22.13. 
prestasen auxilio a los galos ${ }^{11}$. Los Vocates y Tarusates ${ }^{12}$, impresionados por la victoria romana sobre los Sotiates ${ }^{13}$, uno de los pueblos aquitanos más poderosos, se intercambiaron rehenes -obsides- y emprendieron una intensa labor diplomática mediante el envío de embajadas - legationes- con el fin de crear una alianza militar antirromana, a la que se unieron varios Cantabri y gentes que provenían de las civitates más próximas de la Hispania Citerior, llegando a alcanzar los 50.000 efectivos. Entre estos había algunos duces que habían servido bajo las órdenes de Sertorio, a quienes se otorgó el mando por su gran pericia militar. Gracias a esta decisión, las fuerzas coaligadas adquirieron gran destreza adoptando tácticas bélicas propias de los romanos, como la castrametación y las técnicas de hostigamiento, entre ellas la toma de enclaves estratégicos, las emboscadas y el corte de las vías de avituallamiento. Pero las armas romanas prevalecieron y la coalición aquitana fue derrotada perdiendo, según César, las tres cuartas partes de los

11 Caes. Gal. 3.11. Antes de comenzar la campaña, Craso reclutó tropas auxiliares y jinetes entre las civitates fronterizas de Toulouse, Narbona y Carcassone (Caes. Gal. 3.20).

12 Los vocates estarían ubicados en los alrededores de los futuros vasates o de los boiates, es decir, en la región de la actual Bazas o del Pays de Buch (Desjardins, 1878: 363 y 373; Maurin, 1971: 3-4; Bost, 1986: 32). Los tarusates se situarían justo al sur, identificables con la civitas de los aturenses (Aire-sur-l'Adour, Landas) de época imperial (Bost, 1986: 32). L. Maurin opina que los Basaboiates, comunidad citada únicamente por Plinio, haría referencia a una confederación compuesta por los vasates y los boiates. Según el investigador, tras la conquista de Aquitania los dos pueblos se habrían mantenido unidos hasta la creación de la provincia de Novempopulania y de la aparición de la civitas Vasatica, a comienzos del s. IV d.C. (1971: 5 y 15). Es muy posible que los Basaboiates plinianos sean en realidad los Vocates mencionados por César, formados tras la unión de, al menos, dos comunidades diferentes, tras un proceso sinecista.

13 Tradicionalmente se ha admitido la identificación del castro de los sotiates con Sos, en Lot-et-Garonne (Bost, 1986: 25). 
hombres que habían reunido ${ }^{14}$. Tras la victoria de Craso, las fuentes señalan que la mayoría de las comunidades aquitanas enviaron obsides presentando su rendición, entre los cuales se señalan a los Tarbelli, Bigerriones, Ptianii, Vocates, Tarusates, Elusates, Gates, Ausci, Garumni, Sibusates y Cocosates ${ }^{15}$, manteniéndose insumisas algunas de las comunidades más alejadas, confiadas en la llegada del invierno ${ }^{16}$.

Algunos investigadores (Larrañaga, 2007: 77-78; Amela, 2011: 54), en base a la coincidencia cronológica y a la ayuda prestada poco antes por ciertos hispanos fronterizos a los ya mencionados

14 Caes. Gal. 3.20-26. Se cree que esta batalla se dio en los alrededores de Mont-de-Marsan (Bost, 1988).

15 La identificación geográfica y numérica de estos pueblos aquitanos resulta difícil, ya que los autores greco-latinos ofrecen versiones diferentes. Estrabón cita que eran más de veinte pueblos, éthnoi, pequeños y oscuros, de los que solamente menciona tres, Aúskoi, Konovénai y Tarbelloi (4.2.1). César recoge doce nombres: Sotiates, Tarbelli, Bigerriones, Pitiani, Vocates, Tarusates, Elusates, Gates, Ausci, Garumni, Sibusates y Cocosates (Gal. 3.21-27), los Pitiani y Gates solamente son mencionados por él y Sayas cree que el etnónimo Garumni hace referencia a los diferentes pueblos cercanos al río Garona (1992: 171, nota 63); Plinio cita 28 nombres, pero no menciona ni los tres anteriores ni los Tarusates (Nat. 4.108-109), Sayas cree que el texto pliniano incluye en su lista algún pagus; Finalmente Ptolomeo solo menciona cinco (II, 7-9). Fuentes tardoimperiales aportan algunos nombres más, como la mansio Ilurone o la civitas Illoronensium por el Itinerario de Antonino (453.2-3) y la Notitia Galliarum (14) 12. Véase Sayas 1992: 171, nota 65.

16 Caes. Gal. 3.27. Se trataba de pueblos cuyos nombres no nos han llegado, pero que Sayas identifica con gran seguridad con los situados en los territorios del País Vasco continental actual (1992: 161). Esa resistencia la mantuvieron por un tiempo indeterminado, ya que en el 51 a.C. Julio César, durante su estancia en Aquitania, obtuvo rehenes y la sumisión de omnes Aquitaniae civitates, de nuevo, sin especificar cuáles fueron (Hirt. Gal. 8.46.1-2). Fatás piensa que Hircio exagera y que no se habrían sometido todos los pueblos aquitanos (1993: 306). De hecho, hacia el 28 a.C. Marco Valerio Mesala, enviado por Octavio, subyugó a los Tarbelli Pyrene (Tib. 1.7.9), pueblo ubicado en el extremo suroeste aquitano. 
Tarusates y Vocates, creen posible una coordinación conjunta de las revueltas cerretana y aquitana del año 39 a.C. ${ }^{17}$ que analizaremos más adelante. Asimismo, contamos con otras referencias cuyo carácter de coalición militar es más dudoso, ya que deberíamos vincularlas a relaciones más propias de patrón-cliente o a la práctica mercenaria ${ }^{18}$.

Por último, contamos para esta época con nueve tesserae de hospitalidad ${ }^{19}$, halladas todas ellas en el área de influencia de las culturas célticas de la vertiente sur de la cordillera montañosa,

17 App. Sic. 5.92; DC 48.42.4-6; 48.49.2-4; Eutr. Brev. 7.5.

18 En el 211 a.C., el líder ilergete Indíbil comandó un ejército de 7.500 Suessetani en ayuda de los cartagineses contra los romanos (Liv. 25.34). Sobre los hechos: Moret, 1997: 160-161; Brizzi, 2007: 105. En el 52 a.C. Teutomatus, hijo del rex nitiobrigum y amicus de Roma Ollovico, acudió a unirse al ejército de Vercingétorix con numerosos jinetes, algunos de ellos aquitanos (Caes. Gal. 7.31.5). Tal como lo indica Sayas (1992: 167), seguido por Larrañaga (2007: 386, nota 282), esta es la única ocasión en que César alude a unos aquitanos colaborando militarmente con los galos antirromanos. Además, no se concreta si fue una ayuda propiamente dicha o si luchaban a cambio de un sueldo, opción que defiende Deyber (2009: 333). Podría decirse lo mismo de los suessetanos de Indíbil, ya que durante los siguientes años estos vecinos orientales de los vascones fueron socii de los romanos y participaron activamente en el sometimiento de otras comunidades hostiles a Roma. Los suessetanos estaban ubicados al oeste de los Ilergetes. Diversos investigadores han situado a esta comunidad en la región zaragozana de las Cinco Villas, las Bardenas Reales y la zona del municipio navarro de Sangüesa (Fatás, 1971: 119; 1975: 274; Cantón, 2003: 32; 2005: 131; Larrañaga, 2007: 52; Armendáriz, 2008: 257). Sin embargo, a día de hoy su establecimiento exacto es discutido, ya que algunos investigadores optan por situarlos más al norte, en la comarca de Huesca (Pamplona, 1966: 207-208; Beltrán, 2001: 62 y 71). No obstante, Cantón opina que su ubicación en Osca, de ser cierta, debió de ser en una fecha anterior al s. II d.C., ya que Ptolomeo califica a la ciudad oscense como ilergete (2003: 32). En torno al mercenariado en el entorno galo: Deyber, 2009: 249-253.

19 En la Libia berona (Herramélluri, La Rioja) se halló otra tésera, pero hemos decidido no incluirla en el elenco de las fuentes dado 
como es el caso de la Ribera estellesa, bajo la órbita de los berones y la Ribera tudelana, con fuerte presencia celtibérica (Armendáriz, 2009: 329). Aunque no se trate de acuerdos militares propiamente dichos, hemos decidido incluirlos en el elenco de las fuentes por su posible implicación en la constitución de las alianzas bélicas. Las piezas aparecidas pertenecen generalmente a una de las mitades de la tésera, ya que el protocolo establecía la división de las láminas en dos mitades para repartirlas entre las partes firmantes. Seis de las nueve láminas fueron halladas en el ya citado yacimiento de La Custodia (Viana, Navarra), identificado con la Vareia berona ${ }^{20}$. Sin embargo, fueron localizadas fuera de su contexto arqueológico, dificultando su datación exacta, aunque gran parte de los investigadores las sitúan entre los ss. II-I a.C. (Velaza, 1989: 197; Labeaga, Untermann, 1993: 48). De estos seis pactos, cuatro están escritos en alfabeto ibérico y dos en celtibérico, dificultando la identificación de los escasos etnónimos que se recogen en ellas. Por ello, resulta imposible afirmar con rotundidad quiénes fueron las comunidades y/o individuos que se unieron mediante el hospitium (Labeaga, 1987: 458-459; Velaza, 1989: 194-195; Gorrochategui, 1990: 294-295; Labeaga, Untermann, 1993: 50-51; Jordán, 1997: 201 y 203). En el yacimiento de San Sebastián (Fitero-Cintrúenigo, Navarra), se encontraron en circunstancias poco habituales dos téseras más que comparten los mismos problemas que las de La Custodia (Medrano, Díaz, 2003: 403; Díaz Sanz, Jordán, 2006: 260-262). Por último, tenemos el Pacto de Hospitium del despoblado de Lor, en el término del municipio navarro de Cascante y hallado igualmente de forma fortuita, para el cual hay quien ha interpretado el etnónimo Varaka como la Vareia berona (Olcoz, Medrano, 2011:246).

Antes de comenzar con el análisis, procederemos a detallar brevemente la constitución y el funcionamiento de las coaliciones militares en el ámbito galo e hispano, centrándonos en aquéllos en los que se prescindió de la ayuda romana, dejando para otro

su alejamiento geográfico. En torno a dicha tessera, Untermann, 1995: 84 y Jordán, 1998.

20 Véase más arriba. 
momento, por motivos de espacio, las agrupaciones compuestas por locales y romanos. Después pasaremos a analizar el caso concreto de la región circumpirenaica occidental.

\section{2.}

\section{Las coaliciones militares entre}

\section{componentes no romanos en la Galia e Hispania}

Las fuentes escritas señalan que, a la llegada de Roma, las comunidades galas e hispanas tendían a formar coaliciones militares mediante instituciones y mecanismos de fuerte peso tradicional. Los autores clásicos utilizan los vocablos pax, amicitia, fides, clientela y hospitium, junto con otros términos relativos a la consanguinidad, para referirse a dichas alianzas. Algunas veces, dichos tratados toman como base las relaciones existentes desde antaño entre las diferentes comunidades y líderes regionales, pero en otras ocasiones se trata de realidades completamente nuevas, creadas debido a la necesidad (Pérez Rubio, 2011: 5-6; García Riaza, 2013: 19-20). En el primer caso, las previas relaciones amistosas o de fidelidad jugaban un papel determinante, pues podían constituir el primer paso hacia compromisos más serios (Muñiz Coello, 1995: 32). La fides es el elemento central de todas estas relaciones, una relación personal entre individuos o un individuo y una comunidad que se sellaba mediante una ceremonia religiosa donde podía darse un intercambio de regalos -donae-21. La

21 Véase bibliografía recogida en: Nörr, 1996: 15; García Riaza, 2007: 20; Martínez Morcillo, 2014: 339, nota 4. El vínculo de fides era una de las habituales vías hacia las relaciones de clientela o dependencia entre un sujeto poderoso y otros individuos o una comunidad, ya que estos últimos podían acogerse a la protección del primero a cambio de ciertos servicios (Balbín, 2005: 357-358). Estas relaciones, cimentadas en la capacidad militar y cualidades personales del líder, constaban de una aclamación pública de éste como rex o imperator por sus seguidores y, en ocasiones, surgía la consagración extrema conocida como devotio (Ramos Loscertales, 1924; Prieto 
rápida y efectiva articulación de grandes alianzas entre diferentes comunidades galas e hispanas ante el imperialismo púnico y romano indica, como hemos dicho más arriba, la previa existencia de contactos y relaciones. Los pactos de hospitalidad u hospitium que señalan las fuentes escritas representan alianzas solidarias bilaterales efectuadas entre diferentes oppida con otras comunidades o individuos privados, en este contexto, destaca el elevado número de referencias a pactos entre una ciudad y un individuo (Simón, 2008: 132). Inmortalizados en el caso de la Hispania indoeuropea en láminas de metal o tesserae, éstas se concentran en el territorio de Celtiberia y su entorno inmediato, con alguna que otra excepción ${ }^{22}$. Se ha discutido mucho en torno a su utilidad y funcionamiento, ya que las fuentes literarias apenas van más allá de su simple mención indicando las partes beneficiarias. Además, algunas de las láminas se encuentran en muchos casos incompletas y son anepígrafas o están escritas en lengua íbera o celtíbera dificultando de manera notable su interpretación. Asimismo, varias de las piezas carecen de un contexto arqueológico definido por tratarse de hallazgos casuales.

La influencia del hospitium romano está presente en los casos que conocemos, ya que la hospitalidad forjada entre individuos privados tenía como fin asegurarse mutuamente el alojamiento y asistencia en sus comunidades, mientras que el hospitium publicum de ámbito municipal abarca el acomodo anteriormente dicho junto con la concesión de la ciudadanía honoraria a través de un acto oficial (Beltrán, 2010: 280). Así, podemos decir que las comunidades ciudadanas de la Hispania indoeuropea lo

Arciniega, 1978; Dopico, 1998; Peralta Labrador, 2000: 153-168). La práctica de la fides no era un fenómeno del que se beneficiaban exclusivamente los jefes indígenas, prueba de ello es que algunos de los generales romanos más competentes y carismáticos gozaron de amplias redes clientelares entre las comunidades no romanas (Escipión, Sertorio, Pompeyo Magno, César...).

22 Simón Cornago, 2008: 131. Existe una amplia bibliografía en torno a las tesserae de hospitium de la Península Ibérica, véase la bibliografía recogida en las notas de Sayas, 1994: 88-90 y el trabajo de Balbín (2006). 
utilizarían como un instrumento para fortalecer vínculos y facilitar la movilidad cívica (Beltrán, 2010: 281). Como se ha dicho, estos vínculos de hospitalidad privada podían ser la base o complementar un tratado de alianza más general ${ }^{23}$, aunque perdían su valor en caso de que los pueblos a los que representaban los miembros firmantes del acuerdo se declararan la guerra y pasaran a ser enemigos ${ }^{24}$.

Las comunidades interesadas en forjar una alianza contra un enemigo común, procedían a despachar embajadas cuyo fin era llegar a acuerdos y acordar cláusulas que definieran el rumbo y el carácter de la coalición (García Riaza, 2010: 152). Estas alianzas podían estar formadas en base a un pacto global o mediante tratados bilaterales o multilaterales, siendo la existencia de un enemigo común el principal vector cohesionador (Pérez Rubio, 2014: 167; Pérez Rubio et al., 2013: 689). Al ser una relación fundamentada en la fides, se tomaban varias medidas que reforzaban los compromisos y que servían como aval de que se cumpliera lo acordado, como ciertas ceremonias de carácter religioso, la obligación de poner en práctica la estrategia de "tierra quemada" en su propio territorio ${ }^{25}$ y la entrega bilateral o unilateral de rehenes -obsides-26. Así, siguiendo al profesor García Riaza, podemos pensar que los primeros contactos diplomáticos traerían consigo una reunión de alto nivel en la que los líderes pronunciarían ciertos juramentos, garantizando su fidelidad a través de un inmediato

23 Hirt. Gal. 8.3.3.

24 V. Max. 3.2.21; Liv. Per. 103; Oros. 5.8.1.

25 Tal como les exigió en el 52 a.C. Vercingétorix a algunos de sus aliados (Caes. Gal. 7.14.4; 7.15.1).

26 También es posible que se buscara sellar este tipo de tratados mediante un acuerdo matrimonial, práctica común utilizada por los pueblos de la Península Ibérica y por galos, germanos y cartagineses: Asdrúbal se casó con la hija de un rey ibero (DS 25.12) y Aníbal con una princesa de Cástulo, según Silo Itálico, llamada Imilce (Liv. 24.41; Sil. It. 24.41), Viriato contrajo nupcias con la hija del líder hispano Astolpas (DS 33.7) y un princeps celtíbero llamado Alucio con una de las rehenes retenidas por los cartagineses en Cartago Nova (Liv. 26.50), entre otros. 
intercambio o cesión de obsides. Las fuentes apenas detallan el protocolo adoptado durante estas negociaciones (Deyber, 2009: 98; García Riaza, 2013a: 22). En el 52 a.C., varios principes galos se reunieron en un concilium entre los carnutes, confirmando su alianza realizando promesas de fidelidad sobre enseñas militares que contenían un alto carácter religioso ${ }^{27}$. Sin embargo, en el mismo pasaje, César señala que los galos adoptaron esta única medida ante la imposibilidad de realizar un intercambio de rehenes, operación que haría sospechar a los romanos poniendo en peligro los preparativos de la revuelta. No obstante, pudiera ser que ambas iniciativas fuesen complementarias en unas circunstancias no tan extremas como las que se vivían en la Galia en aquella época. Sobre la identificación de los rehenes entregados, se piensa que se trataría de hijos varones ${ }^{28}$, seguramente adolescentes ${ }^{29}$, pertenecientes a las élites de las comunidades implicadas. Tras la entrega, estos obsides serían confinados en lugares seguros y retenidos

27 Caes. Gal. 7.2.1-3.

28 En cuanto al sexo de los rehenes tomados por Roma, se piensa que la mayoría de ellos corresponderían al género masculino, aunque también había mujeres (Plb. 10.18.3 y 13; Liv. 26.49.11-16; Flor. 1.22 .40 ), pero la gran mayoría de los ejemplos femeninos se remiten al Mediterráneo oriental (Allen, 2006: 180-181; Álvarez Pérez-Sostoa, 2009: 263-267). Elbern, en cambio, señala que la toma de mujeres era una excepción puesta en práctica entre aquellos gobernantes occidentales que no tenían descendencia masculina (1987: 99-106), lo cual podría indicar que los estados orientales sí tenían esa costumbre y eran ellos los que enviaban voluntariamente a mujeres (Álvarez Pérez-Sostoa, 2009: 266).

29 Según los tres únicos tratados republicanos que han sobrevivido (recogidos en: Plb.15.18-19; 21.32.8-10; Liv. 30.37; 38.38), se dejaban fuera a los menores de 12 años y a los mayores de 40 años o más, las condiciones de mantenimiento variaban en cada caso. A los griegos se les exigía entregar más rehenes en caso de fallecimiento, y en el cartaginés, renovar el grupo de rehenes cada cierto tiempo (mutatio obsidum). También habría rehenes niños, por ejemplo, los que mantenían los cartagineses en Carthago Nova y que fueron liberados por Publio Cornelio Escipión cuando éste les arrebató la ciudad en el 209 a.C. (Plb. 10.3). 
mientras existiera la coalición (Lee, 1991: 369-370; García Riaza, 1997: 89; Allen, 1999: 76; Álvarez Pérez-Sostoa, 2009: 267-279). La promesa de botín también debió de ser un aliciente importante en la creación de alianzas, tal como se atestigua en los numerosos ejemplos que conocemos entre los pueblos celtíberos, galos, germanos y britanos (Deyber, 2009: 73-75; García Riaza, 2013: 17; Pérez Rubio et al. 2013: 686; Martínez Morcillo, 2014: 342).

Los representantes de las comunidades coaligadas se reunían en un concilium, seguramente en lugares propicios para ello que podían tener cierto significado religioso y que servían como punto de encuentro o frontera, tal como sucede en el mundo ibérico con los yacimientos de Serreta de Alcoy (Alicante), el Collado de los Jardines de Despeñaperros y el de Castellas (Jaén), el enclave de Pesinunte entre los gálatas y la ya citada región de los carnutes para los galos (Pérez Rubio, 2011: 30-31). Según se desprende de las fuentes, estas alianzas eran dirigidas por un órgano colegiado encargado de tomar las decisiones más importantes, como la cantidad de contingentes que debía entregar cada pueblo ${ }^{30}$, la elección de los jefes militares, el envío de embajadas y la firma de los acuerdos de rendición ${ }^{31}$. No sabemos si estas asambleas eran convocadas con asiduidad (Moret, 1997: 158). Es posible que las legationes que despachaban estuvieran formadas por los representantes de todos los miembros coaligados (Pérez Rubio, 2014: 167; Pérez Rubio et al., 2013: 689), tal como pudo haber sucedido en 182 a.C., cuando un gran ejército celtíbero envió a 10 legados a entrevistarse con Tiberio Sempronio $\mathrm{Graco}^{32}$. A pesar de que conozcamos casos en los que la autoridad militar recae en un solo

30 Las 15 civitates belgas que se alzaron contra César decidieron en concilium el número de guerreros que aportaría cada una a la coalición (Caes. Gal. 2.4.4).

31 Ciprés, 2002: 142; Pérez Rubio, 2011: 36-38. El concilium de ciudadanos de los pueblos ibéricos vencidos por Escipión en el 205 a.C., decidió la ejecución de los responsables de la derrota, Mandonio et ceteri principes, precio además exigido por los romanos para negociar la paz (Liv. 29.3.1-5; 34.20.1-3; 40.30.2; Str. 3.3.5).

32 Liv. 40.47.

En defensa del territorio: las coaliciones militares... 
hombre ${ }^{33}$, las fuentes señalan frecuentemente la designación de un mando conjunto para que dirija las operaciones ${ }^{34}$. Todos ellos fueron proclamados jefes de coaliciones a través de fórmulas tradicionales, que incluye política matrimonial y reconocimientos públicos de autoridad con fuerte peso de elementos religiosos ${ }^{35}$. Sin embargo, a pesar de la elección de uno o dos generales que guiasen al colectivo en la batalla, cada contingente aliado marchaba al combate bajo las órdenes de su propio jefe militar, avanzando no unidos sino añadidos unos a otros, formando el ejército confederal (Muñiz Coello, 1994: 98).

Estas alianzas entre los pueblos de la Galia y la Península Ibérica demostraron un poder de convocatoria nada desdeñable, llegando a agrupar varias decenas de miles de hombres ${ }^{36}$. A veces

33 Indíbil (Liv. 25.34), Viriato (App. Iber. 62 y 75), Olónico u Olíndico (Liv. Per. 43; Flor. 1.33), Ariovisto (Caes. Gal. 1.30-54) o Vercingétorix (Caes. Gal. 7.4.4), entre otros.

34 Como los "celtas" Istolacio e Indortes comandando un ejército tartesio (DS 25.10); Budar y Besadines frente a una coalición de hispani en 217 a.C. (Liv. 33.44); los galos Moenicapto y Vismaro, insignes reguli Gallorum, dirigiendo un ejército hispano aliado de los cartagineses (Liv. 24.42.7-8); los celtíberos Caro y Megaravico (Flor. 1.34.4) y Ambón y Leucón (Flor. 1.34.2; App. Iber. 45); y los ilergetes Indíbil y Mardonio (García Riaza, 1998-1999: 206).

35 Plb. 10.10.9; 10.40.1-7; DS 21.1; 25.2.3-7; 25.12; DC fr. 57.42-48.

36 En el 225 a.C., en la batalla de Telamón los romanos vencieron a una coalición de galos de la Galia Cisalpina, dejando en el campo de batalla los cuerpos de 40.000 enemigos y realizando 10.000 prisioneros (Plb.2.31.1-2); Al año siguiente cayó derrotado un ejército de 50.000 galos insubres (Plb. 2.32.6); pero poco después consiguieron sumar a sus guerreros supervivientes las fuerzas de los galos gesatos, alcanzando la cifra de 30.000 hombres (Plb. 2.34.2); En el 205 a.C. el líder ilergete Indíbil sublevó a su pueblo, a los ausetanos y a otras comunidades vecinas reuniendo un ejército de 30.000 infantes y 4.000 jinetes (Liv. 29.1.26). Cinco años después, un ejército confederal galo formado por boyos, insubres, celinos, ilvates y ligustinos sufrieron 35.000 bajas entre muertos y apresados, perdiendo numerosos estandartes (Liv. 31.10.2; 31.21.17). En el 185 los romanos tuvieron que hacer frente en la Carpetania a una coalición de Hispani de 35.000 hombres (Liv. 39.31); en 181 a.C. los 
las fuentes no señalan el carácter de coalición de la fuerza concentrada, pero dado el tamaño elevado de muchas de ellas no es aventurado suponer que se trataba de coaliciones. En el periodo de la Roma republicana y altoimperial, el derecho a celebrar el triunfo estaba ligado al número de enemigos derrotados, por ello, se tendía a exagerar estas cifras. Es por eso que varios investigadores opinan que el número de muertos y de captivi que recogen las fuentes distaría bastante de la realidad (Pina, 2006: 118). En cambio, otros piensan que se trata de cifras plausibles, pues en las ocasiones en que se señala el volumen de enseñas capturadas, éstas coinciden en proporción con el de los muertos y heridos y recientes cálculos en torno a la densidad de población de la Celtiberia, tratan de dar por válidas los datos ofrecidos por las fuentes ${ }^{37}$. Sean falsas o no, estas cifras intentan mostrarnos que se trataba de cantidades superiores a la tónica habitual. Además, desde el punto de vista táctico muestran cierto desarrollo, pues son fuerzas que utilizan el sistema de castrametación (en ocasiones cada pueblo

celtíberos lograron reunir 35.000 guerreros, según Livio, el mayor ejército que lograron poner en pie hasta la época (Liv. 40.30) y tras ser derrotados, consiguieron reagruparse y con la ayuda de nuevos contingentes acudieron a auxiliar la ciudad de Contrebia (Liv. 40.33); Poco después, en la batalla del Mons Chaunus (quizá el Moncayo), los celtíberos tuvieron 22.000 bajas y les fueron capturadas 72 enseñas (Liv. 40.50); En el 175 a.C. Tiberio Sempronio Graco venció a los sardos de Cerdeña realizando 80.000 cautivos (Liv. 41.28.8-10); Asimismo, en el 154 a.C. el ejército de belos y arévacos, al mando de Caro y Megaravico, llegaba hasta los 20.000 infantes y 5.000 jinetes (Flor. 1.34.4) y en la revuelta del 95-94 a.C. perdieron la vida 20.000 guerreros celtíberos (App. Iber. 99-100). En el 84 d.C., los britanos revelados consiguieron reunir un ejército de 30.000 almas (Tac. Agric. 29.4).

37 Véase las reflexiones y la bibliografía recogida en: Ciprés, 2002: 145; Pérez Rubio, 2014: 166; Pérez Rubio et al., 2013: 685. Otro de los argumentos en torno a la veracidad de las fuentes señala el gran número de bajas que se indican para el bando romano, especialmente entre sus aliados. Sin embargo, no podemos perder de vista que dichas cifras podrían haber sido infladas para engrandecer el triunfo y el esfuerzo realizado por los generales romanos. 
levanta su propio campamento), tejen redes de avituallamiento, utilizan enseñas y estandartes, aplican estrategias de tierra quemada, hacen uso del fuego para facilitar su retirada y son capaces de plantear batallas campales adoptando distintas formaciones, realizar emboscadas, labores de hostigamiento, persecuciones y de conjugar caballería e infantería ${ }^{38}$.

La coalición podía ser disuelta oficialmente por el concilium que lo estaba dirigiendo, generalmente después de haber alcanzado los objetivos militares para los que se había creado o tras haber sufrido una derrota irreversible en el campo de batalla. En caso de que los tratados se hubieran visto avalados por un intercambio de rehenes anterior, se procedía a la devolución de los mismos. Por su parte, los integrantes de la alianza también podían abandonar la formación cuando considerasen que no se habían respetado las cláusulas acordadas ${ }^{39}$. No obstante, la decisión de romper los compromisos podía traer perjuicios graves, los rehenes entregados perdían su estatus inviolable y pasaban a convertirse en meros captivi pudiendo ser vendidos como esclavos o utilizados para coaccionar a su comunidad de origen (Allen, 2006: 63-66). En ocasiones las fuentes señalan cómo la práctica institucional cotidiana originaba mecanismos de compensación que paliasen los efectos de la ruptura de fidelidades dependiendo del daño ocasionado y la categoría social de la víctima, como una nueva entrega de rehenes o el pago de una multa que consistía en cabezas de ganado, armas, pieles etc. ${ }^{40}$ Las fuentes señalan que estas coaliciones se ven influidas notablemente por las rivalidades y tensiones preexistentes entre los pueblos que las conforman, gran parte de las veces por la búsqueda de supremacía regional por parte de algunos líderes locales o comunidades, como es el caso de los ilergetes en el entorno de la costa catalana e interior (Blázquez, 1996: 112). Asimismo, dentro de cada comunidad existían facciones opuestas inmersas en frecuentes luchas aristocráticas cuya

38 Caes. Gal. 1.5.4; 3.20.3; 7.15.1-4; 7.28.6; Liv. 28.1.7; 29.2.1-5; 34.19; 35.7.6-8; 39.30; 40.30; 40.33; Tac. Agric. 29.4, por ejemplo.

39 Liv. 34.20.4-9; 40.49.

40 Tac. Germ. 12.2; 21.1; App. Iber. 53/54; DS 34.10; Str. 6.4.3. 
alternancia en el poder podía traer consigo cambios importantes en la política exterior, llegando a romper hasta los lazos unidos mediante el matrimonio ${ }^{41}$.

Dadas las características del presente estudio, opinamos que con lo dicho hasta ahora es suficiente para abordar el tema que nos ocupa, el de las alianzas militares forjadas contra las fuerzas romanas a lo largo del proceso de conquista de las regiones occidentales de la cordillera pirenaica.

\section{3.}

\section{Las coaliciones militares antirromanas en el territorio}

Como hemos podido comprobar, la gran mayoría de las veces las fuentes grecolatinas se muestran parcas a la hora de identificar a las comunidades que conformaban las coaliciones compuestas únicamente por elementos no romanos. Del relato de Livio en torno al choque habido entre las tropas del pretor Lucio Manlio Acidinio y un ejército celtíbero hacia el 188/187 a.C., solamente podemos afirmar que este último era en realidad una fuerza de gran tamaño. Tal como se ha indicado, la increíble cifra de 10.000 muertos y 2.000 prisioneros parece un tanto exagerada con el objetivo de agrandar la victoria romana y dar cuenta de la dificultad de la campaña. Pero no debemos perder de vista que, tras salir perjudicados en un primer embate, los celtíberos fueron capaces de reorganizarse para luchar de nuevo sufriendo grandes pérdidas (Pérez Rubio et al., 2013: 678; Pérez Rubio, 2014: 166). En opinión de Cantón, con quien estamos de acuerdo, en este pasaje el término Celtiberi podría encubrir ciertas realidades étnicas

41 Contamos con numerosos ejemplos, entre otros, el caso de Cástulo en la Segunda Guerra Púnica (Liv. 24.41; 28.20); la comunidad de los belos durante la Segunda Guerra Celtibérica (García Riaza, 2002: 274-275); o las distintas luchas entre los notables heduos, que llevó a que su pueblo quebrara la amistad con los romanos para abrazar la revuelta liderada por Vercingétorix (Caes. Gal. 7.55.1-6). 
menores del Valle Medio del Ebro (2003: 43). Desconocemos si tras el primer encuentro recibieron refuerzos o si disponían de fuerzas de refresco: más arriba hemos visto que en ocasiones dejaban algunos destacamentos cuidando el campamento o la retaguardia, quizá en el oppidum de Calagurris ${ }^{42}$, cerca del cual tuvo lugar la segunda batalla. Sobre las acciones de Tiberio Sempronio Graco contra los celtíberos, éstos últimos fueron derrotados en el entorno de Mons Chaunus aun tras haber reunido un gran ejército. A pesar de la posterior fundación de Gracchurris a orillas del Ebro, los autores grecorromanos no señalan si se realizaron acciones militares en territorio vascón más allá de dicha refundación. Todo esto nos lleva a suponer que algunas comunidades que firmaron los acuerdos de rendición de Graco pudieran corresponder al territorio vascón, suessetano o berón. Así, Armendáriz opina que para erigir la nueva ciudad, el general romano habría castigado o neutralizado cualquier otro núcleo indígena fuerte que hubiera en el entorno ${ }^{43}$. Asimismo,

42 Livio, como hemos dicho, emplea a lo largo de su obra los imprecisos términos de urbs y oppidum para referirse a Calagurris (Bedon, 2003: 243, nota 46). La adscripción étnica de Calagurris con anterioridad a las Guerras Sertorianas, celtíbera para algunos, vascona para otros, ha creado un debate historiográfico, ya que se ha utilizado como un argumento más de la teoría que defiende la existencia de una "expansión vascona" sobre sus vecinos del sur y del este (Lanz, 2016b: 42-43, nota 41).

$43 \mathrm{El}$ investigador sospecha especialmente que pudiera ser el oppidum de El Castillo de Castejón (Navarra), que fue hasta entonces el núcleo referencial de la zona (2008: 205 y 216; 2009: 329). Además, el arqueólogo señala que la civitas Ergavica mencionada por Livio en ese mismo año, relacionada tradicionalmente con el núcleo conquense, podría corresponder a la Ergavica vascona citada por Ptolomeo, a día de hoy sin identificar y que en su opinión debe ubicarse en la ribera del Ebro (2008: 23). Algunos investigadores han tratado de situar la ciudad vascona de Ergavica en Navarra, en el municipio de Milagro (Schülten, 1927: 231; Bosch Gimpera, 1932: 444) o en Berbinzana (Canto, 1997: 51-52; Castiella, 2003: 262). Creemos que es más posible hallarla en algún lugar del curso alto del río Ega (Peréx, 1986: 149; Sayas, 1994: 33; Ramírez Sádaba, 
varias intervenciones arqueológicas muestran toda una serie de oppida destruidos violentamente en la primera mitad del s. II a.C. a lo largo de la ribera navarra, que pudieran estar vinculados con la Guerra Celtibérica ${ }^{44}$.

Las fuentes en torno a la relación del 77 a.C. entre autrigones y berones, aunque fragmentarias, ofrecen un panorama algo más claro. Sabemos que entre ambas comunidades existía cierto tratado que garantizaba el auxilio militar, al menos, hacia los berones y más concretamente hacia los vareienses. Armendáriz lanzó la idea de que, quizá, los jinetes autrigones y berones que acudieron a defender Vareia actuarían en conformidad con los compromisos de hospitalidad que tenía la ciudad con los oppida vecinos y con las familias más influyentes de la región (2008: 279), unos compromisos que pensamos pudieron haber sido la base de una alianza militar. Siguiendo la misma tónica, otros afirman que la tessera de Cascante ha de situarse en este contexto, señalando que, en su expedición hacia la civitas berona, Sertorio atacó a los cascantenses debido a que habrían sellado una alianza con los vareienses (Olcoz, Medrano, 2011: 250). Esta hipótesis también podría abarcar en su seno a la pieza fiterana, ya que apareció cerca del oppidum cirbonero de San Sebastián, atacado y destruido por las fuerzas sertorianas. Sin embargo, dichos investigadores prefieren identificar el citado yacimiento como uno de los campamentos de campaña del general sabino (Olcoz, Medrano, 2008: 115), cuando seguramente debería ligarse a la comunidad que

2002: 23 y 29; Andreu, 2006: 206) o en el despoblado de Yerga, próximo a Fitero, Navarra (Ramírez Sádaba, 2009: 130-131).

44 Entre ellos tendríamos el yacimiento de Los Forcos en Azagra, Parralejos en Lapoblación, Cogote Hueco en Mendavia, El Abad de Lodosa, Cabezo de la Mesa en Ablitas y Peña del Saco en Cintruénigo (Armendáriz, 2008: 263). A pesar de que la destrucción del poblado de La Hoya (Laguardia, Álava) se ha fechado tradicionalmente en el s. III a.C., el arqueólogo navarro no descarta llevarla hasta la primera mitad del siglo siguiente, "momento cronológico a partir del cual muy posiblemente haya que situar la ocupación celtibérica que registra la villa medieval de Laguardia" (2008: 266), observación que comparte el arqueólogo Peñalver (2008: 250). 
habitaba en el castro destruido. Sea como fuere, desconocemos el número de guerreros que fue capaz de convocar la alianza entre autrigones y berones, aunque parece que no fueron lo suficientes como para defender con éxito la civitas de Vareia (Arméndariz, 2008: 282).

En cuanto a la coalición del 56 a.C., hemos visto que los artífices del mismo fueron los Vocates y Tarusates y que recibieron auxilia et duces de las civitates hispanas de la Citerior más cercanas a su territorio y de algunos Cantabri. Según César, los aquitanos enviaron legati a todas partes en busca de apoyos y lograron reunir una fuerza de 50.000 hombres, una cifra que cada día iba en aumento y que hizo que los romanos tomaran la iniciativa atacando ellos primero. El auxilio solicitado a las civitates hispanas y la solidaridad que mostraron estas demuestra la existencia de unos contactos y de relaciones previas entre las comunidades de ambos lados de la cordillera pirenaica. En cambio, cuesta identificar a estas ciudades que respondieron a la llamada de socorro. Según Sayas, debemos descartar que éstas fueran vasconas a pesar de su cercanía ${ }^{45}$, ya que en ningún momento se menciona que participasen en la contienda gálica. Al parecer mantenían relaciones amistosas con los romanos y puede que se mostrasen reacios a servir bajo las órdenes de los antiguos oficiales de Sertorio, pues años atrás habrían sido fieles a su rival Pompeyo, exceptuando a los calagurritanos (1992: 164). Sobre los cántabros mencionados, el historiador navarro piensa que se trataría de las comunidades del norte peninsular que se mantuvieron insumisas hasta que fueron sometidas durante las Guerras Astur-cántabras (26-19 a.C.) y rechaza la hipótesis que defiende que en el relato cesariano se utilizara el término Cantabri para referirse genéricamente a todos aquellos pueblos bañados por el mar Cantábrico (1992: 164, notas 37 y 38 ). En cuanto al lugar de procedencia de los antiguos oficiales de Sertorio, las fuentes indican que vinieron de las civitates

45 Salinas de Frías opina que junto con los cántabros, los aquitanos también fueron ayudados por vascones. Asimismo, sugiere cierta vinculación entre estos hechos y la rebelión vaccea ocurrida por las mismas fechas (1995: 104-105). 
hispanas más próximas a Aquitania. Algunos investigadores se han aventurado a sugerir que quizá proviniesen de Lugdunum Convenarum (actual Saint-Bertrand-de-Comminges), fundado por Pompeyo Magno con los restos del ejército sertoriano hacia el 72 a.C. (Konrad, 1990: 40), o de las civitates de los celtíberos, jacetanos y cerretanos (Fatás, 1993: 304). Tras la derrota, hemos visto que numerosas comunidades aquitanas, incluidas las de los Vocates y Tarusates, enviaron rehenes a Craso mostrándole su sumisión. Desconocemos si todas ellas habían formado parte de la coalición y, de ser así, si hubieran aportado tropas. Cabe resaltar que en la lista ofrecida en los Commentarii no se menciona a los Lactorates, cuya capital se ubicaba en Lactora (actual Lectoure, Gers), que lindaban con la provincia romana. Es posible que colaborasen con las tropas cesarianas en la conquista del territorio, pues no participaron en la resistencia frente al invasor y César no los menciona entre las comunidades que se le sometieron en deditio $^{46}$.

En el 51 a.C., el ex triunviro decidió pasar la última parte del verano en la Aquitania, pues no la conocía personalmente. Al

46 En el 55 a.C., durante una refriega entre un grupo germano y unos jinetes de César, perdieron la vida setenta y cuatro de estos últimos, entre ellos el vir nobilissimus aquitano Piso y su hermano, cuyo abuelo, según César, fue rex de su civitas y poseía el título de amicus por parte del Senado romano (Caes. Gal. 4.12). Seguramente Pisón y su hermano perteneciesen a la comunidad de los Lactorates, que seguirían siendo considerados amici por parte de Roma (Larrieu-Duler, 1972: 16 y 18; Clémens, 1981: 88; Gardes, 2001: 126; Larrañaga, 2007: 74, nota 167). Cabe la posibilidad de que Pisón y su hermano se encontrasen entre los numerosos equites reclutados en los rebordes orientales de la Aquitania independiente a los que Publio Craso llevó consigo en su campaña del 56 a.C. No sabemos si los dos vires nobilissimi estaban acompañados por más miembros de su comunidad de origen, aunque es posible que sí. Asimismo, puede que hubiese lactorates entre los jinetes aquitanos que se llevó César en el 49 a.C. a luchar a Hispania. Para una bibliografía básica en torno a los lactorates así como los debates historiográficos en torno a ellos durante la Guerra de las Galias: Bost, 1986: 29, nota 60. 
personarse con dos legiones, todas las comunidades de la región -omnes Aquitaniae civitates- le enviaron embajadas entregándole rehenes ${ }^{47}$. Tras estos hechos, los aquitanos se mantuvieron sumisos, al menos, hasta el 39 a.C. Esta vez Octavio envió al propio Marco Agripa a sofocar la revuelta. No obstante, según Dion Casio, fue un tumulto que apenas tuvo importancia y Apiano indica

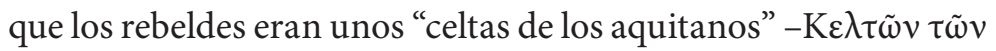

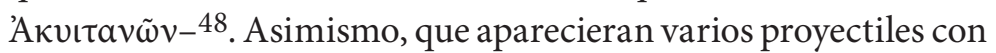
el cuño de Agripa en el oppidum de los nitióbroges ${ }^{49}$, nos lleva a pensar que el conflicto se focalizó en esa región sin que se llegase a propagar entre las poblaciones aquitanas subgarónicas. En cambio, la ofensiva dirigida ese mismo año por el legatus Domitius Calvinus contra los cerretanos tuvo lugar probablemente en el Pirineo central peninsular, más concretamente a la altura de Osca, ya que es aquí donde Domicio mandó emitir moneda (Fatás, 1993: 308; Rivero Gracia, 2002: 162-163). En conclusión, opinamos que aunque coincidieran en el tiempo, es muy poco probable que los cerretanos y los nitióbroges actuasen de manera conjunta contra la ocupación romana, mucho menos que hubiesen forjado ningún tipo de alianza.

Como se ha dicho más arriba, el compromiso que unía y vertebraba estas alianzas era la defensa del territorio contra Roma, incluso en el caso de la entente autrigón-berón que, aunque no sepamos con certeza su actitud respecto a la dominación romana, se mostraban reacios a soportar la autoridad de Sertorio. Todos ellos actuaron dentro de su territorio o ámbito de influencia, afirmación que cobra fuerza si admitimos que detrás del término "celtíbero" que se emplea para narrar los acontecimientos de la década del 180 puedan ocultarse comunidades locales menores. En cuanto al protocolo seguido para la formación de dichas coaliciones,

47 Aul. Hirt. Gal. 8.46.1-4.

48 App. Sic. 5.92; DC 48.49.2-4; Eutr. Brev. 7.5.

49 Verdin, 2013: 70. La comunidad de los nitóbroges era de origen celta y su oppidum principal era Aginnum (actual Agén, Lot-et-Garonne). Su rey Olovicón fue nombrado amicus por el Senado romano por las buenas relaciones entre ambos (Caes. Gal. 7.31.5.). 
el único caso que nos aporta cierta información al respecto es el recogido por los Comentarii ${ }^{50}$. De esta forma, según César, tan pronto como Craso derrotó a los aquitanos Sotiates, los Vocates y Tarusates, tras alcanzar un consenso en algún lugar y siguiendo unas pautas que desonocemos, despacharon legati a todas partes, sin indicar su número y señalando de forma indirecta algunos de los destinos, como las civitates hispanas fronterizas, pero es casi seguro que también lo fueran el resto de las comunidades aquitanas que no habían sido sometidas y, posiblemente, Cantabria. Alcanzamos a indagar que dichas embajadas fueron organizadas por los senati locales de los citados pueblos y que los hombres escogidos para tal fin, aunque nos sea imposible saber su número, serían los mejores disponibles en ese momento, pues se trataba de una situación extremadamente desesperada. Estas legaciones tuvieron el éxito esperado, pues acudieron numerosos guerreros a la llamada de socorro, muchos de ellos provenientes de las civitates quae sunt Citerioris Hispaniae finitimae Aquitaniae y de Cantabria. De hecho, en los Comentarii se cita que Craso decidió emprender la lucha porque día tras día aumentaban los efectivos del ejército aquitano con hombres que venían de todas partes (Caes. Gal. 3.27), señal de que los tarusates y vocates vieron superadas sus expectativas de recibir ayuda. Desconocemos la proporción de las tropas aportadas por los miembros de la coalición la cantidad exacta de los guerreros llegados de la Península Ibérica.

Ambas comunidades aquitanas, tan pronto como se reunieron en concilium para organizar la defensa y enviar las citadas legationes, intercambiaron rehenes con el fin de garantizar el compromiso de ayuda mutua. Estos obsides habrían sido seleccionados entre los hijos adolescentes de las élites de ambos pueblos y serían confinados en el oppidum principal de cada uno de ellos. Entre

50 Las tesserae de hospitium poco nos pueden decir sobre aquellos que las realizaron y menos aún sobre cuáles fueron los motivos o las necesidades que los impulsaron. Tampoco conocemos qué fórmulas diplomáticas siguieron, ni si hubo condiciones que avalasen lo acordado, como por ejemplo, el intercambio de obsides entre ambas partes, al contrario de lo que ocurre en el caso aquitano. 
las cláusulas del acuerdo, se especificaría el carácter temporal de este confinamiento, ya que se trataba de una cooperación motivada por un hecho puntual. De esta forma, con la disolución de la sociedad los rehenes habrían sido devueltos. En cuanto a las razones que indujeron a los hispanos a responder afirmativamente a la llamada de auxilio, es posible que sintieran una mayor afinidad y cercanía con los aquitanos que con los romanos, a pesar de que las civitates fronterizas citadas por César estuvieran integradas en el marco de la provincia Tarraconense. La esperanza de obtener botín pudo favorecer de manera importante en dicha decisión, al igual que ocurría con los pueblos celtíberos, galos, germanos y britanos (García Riaza, 2013: 17; Pérez Rubio et al., 2013: 686). No sabemos si hubo otros intercambios de rehenes más allá del habido entre vocates y tarusates.

Como se ha dicho, en ocasiones el concilium de los coaligados ponía al frente de la dirección de las operaciones militares a jefes de gran prestigio, sin importar que tuvieran un origen foráneo. De nuevo, solamente conocemos el caso de la gran alianza aquitana del 56 a.C., pues la escueta información sobre las ya citadas acciones celtíberas y el carácter mutilado de los pasajes que recogen el impacto de las Guerras Sertorianas en el territorio, nos imposibilitan saber la identidad de los dirigentes militares de los celtíberos, berones y autrigones. De todas formas, se percibe cierta organización y desarrollo de tácticas bélicas, como la capacidad de los celtíberos de recomponerse y volver a presentar batalla tras sufrir una grave derrota hacia el 188/187 a.C., no sabemos si haciendo uso de tropas de refresco o tras recibir nuevos refuerzos, y las acciones de hostigamiento llevadas a cabo por los jinetes autrigones y berones a los forrajeadores y vías de abastecimiento de las fuerzas sertorianas mientras estas asediaban Contrebia Leuca$d e^{51}$. Hemos visto que los aquitanos decidieron poner al frente de

51 Liv. Per. 41. Ubicado en el término de Aguilar del Río Alhama, La Rioja. Es posible que los celtíberos a los que se enfrentó Tiberio Sempronio Graco en Mons Chaunus, identificado con el Moncayo, hubiesen elegido dicho lugar pensando que el buen conocimiento de la orografía montañosa pudiera favorecerles en la lucha. 
sus tropas a aquellos duces hispanos que acompañaron a Quinto Sertorio, hombres experimentados que tenían fama de conocer bien el arte de la guerra. Esta decisión tuvo su repercusión en el desarrollo de la contienda, ya que, por influencia de estos duces, la gran coalición adoptó ciertas técnicas militares romanas poniendo en serios apuros a los contingentes de Craso. Las fuerzas reunidas por los aquitanos trataron de obligar la retirada de los invasores romanos mediante un continuo hostigamiento, ocupando puestos de vigilancia, fortificándose en campamentos y cortándoles las comunicaciones y vías de suministros. Según señala César, el objetivo de esta estrategia era forzar a Craso a que abandonara la región para caer sobre él y su ejército una vez comenzaran a replegarse. El joven comandante, al percatarse de las intenciones de los enemigos y de que cada día aumentaban en número, decidió presentar batalla pero los aquitanos prefirieron no salir de su campamento, confiados en que obtendrían mejores resultados si continuaban actuando como hasta entonces (Caes. Gal. 3.23-24). Es posible que también prefirieran esperar a aumentar el número de efectivos en los siguientes días, una de las razones por las que las tropas cesarianas decidieran iniciar el ataque. A pesar de resistir tenazmente en un ataque frontal a su campamento fortificado, la coalición dejó desprotegida la puerta trasera del mismo, lugar por el que penetró un destacamento romano que se había trasladado hasta allí sin que se dieran cuenta los defensores. Finalmente, cercados por los atacantes, muchos guerreros trataron de huir pero la gran mayoría fueron batidos por la caballería romana que se lanzó en su persecución que duró hasta caer la noche. Según César, sólo quedó con vida una cuarta parte de los 50.000 hombres que lograron reunir los Vocates y Tarusates (Caes. Gal. 3.25-26).

La derrota militar trajo la disolución de estas alianzas. Aunque en el caso del ejército celtíbero vencido cerca de Calagurris no lo podemos afirmar con rotundidad, las graves pérdidas sufridas pudieron haber sentenciado la supervivencia de esta coalición. Los pactos establecidos por Graco y la fundación de Gracchurris trajeron un periodo de convivencia pacífica a la región, por lo que suponemos que las comunidades anteriormente sometidas habrían roto los acuerdos militares. Nada sabemos de la relación 
entre berones y autrigones a partir del año 76 a.C. Según hemos podido ver, colaboraban contra los sertorianos desde antes de haber entrado en contacto con Pompeyo y el pasaje de Livio que recoge la expedición de Sertorio remontando el Ebro se corta en vísperas del ataque sobre el oppidum berón de Vareia. Hay quien ha sugerido que el general sabino habría continuado río arriba llegando hasta territorio autrigón e incluso caristio y várdulo (García Mora, 1991: 210-211), pero a nuestro parecer se trata de una hipótesis demasiado aventurada a falta de fuentes que la avalen. Para acabar, una vez se supo la victoria de Craso, vocates, tarusates y gran parte de las comunidades aquitanas, enviaron rehenes sometiéndose a la autoridad romana, dando por concluido el acuerdo militar. Como hemos dicho, es de suponer que se habrían devuelto los obsides intercambiados durante las negociaciones y la creación de la alianza, ya que éstos habrían perdido su función inicial.

Las coaliciones militares analizadas, de entre las cuales destaca la forjada en el 56 a.C. en Aquitania, señalan un dinamismo político y diplomático similar al de otras regiones de la Galia y de Hispania, con unos mecanismos parejos que permitían desarrollar un potencial militar notable capaz de hacer frente de manera efectiva a ejércitos romanos. El envío de embajadas y la capacidad de llegar a acuerdos demuestran la existencia de unas herramientas y estructuras comunicativas bien asentadas anteriores a la llegada de los romanos que llegan a reunir varias comunidades en momentos de máxima tensión, como es el caso de la expedición de castigo de Sertorio sobre el territorio berón en el 76 a.C. o la gran alianza aquitana. Tal como lo señala el profesor García Riaza, esta realidad indica que "la guerra no es el fracaso de la diplomacia, sino más bien, en ocasiones, una consecuencia de ésta: el fruto de las iniciativas de cohesión local ante una amenaza exterior" (2010: 153).

Una vez pacificada la Aquitania, Octavio Augusto amplió sus fronteras integrando en ella varias comunidades galas que habitaban entre los ríos Loira y Garona, siguiendo una perspectiva más administrativa que cultural y equilibrando de esta manera la nueva estructuración provincial romana en la Galia. Las autoridades 
romanas, sabedoras de la actuación conjunta y gran poder de convocatoria de los aquitanos durante la Guerra de las Galias, además de su potente conciencia identitaria y peculiaridad cultural, tratarían con la nueva delimitación provincial difuminar y debilitar esa cohesión étnica obligándoles a compartir la nueva demarcación administrativa con algunos pueblos celtas (Sayas, 1992: 168-169). De ser así, los esfuerzos romanos no habrían servido de mucho, ya que a finales del siglo III d.C. comprobamos que todavía existe una organización y cohesión interna y un sentimiento localista muy fuerte entre los aquitanos originales, ahora Novem Populi, una realidad peculiar que los llevó a enviar una embajada al emperador pidiendo un trato diferenciado respecto a sus vecinos los galos (Lanz, 2016a: 547-548).

\section{Fuentes utilizadas}

App. Sic. = Appianos, De rebus Siculis et reliquarum insularum, ed. de Mendelssohn L. (1879): Appianos, De rebus Siculis et reliquarum insularum. Leipzig: Teubner.

Caes. Gal. $=$ Caius Julius Caesaris De bello gallico, ed. de Hering W.C. (1997): Iuli Caesaris commentarii, I: Commentarii belli gallici. Leipzig: Stuttgart; y ed. bilingüe de Lopetegi, G. (1999): Galietako Guda, Gaio Julio Zesar. Sarrera, itzulpena eta oharrak. Vitoria-Gasteiz: Universidad del País Vasco-Euskal Herriko Unibertsitatea.

DC = Cassius Dio, Historiae Romanae, ed. de Cary, E. et al. (1914): Cassius Dio, Historiae Romanae. London-New York: Harvard University Press.

DS = Diodorus Siculus, Bibliotheca historica, ed. de Bekker, I. et al. (1888-1906): Diodorus Siculus, Bibliotheca historica. Leipzig: Teubner.

Eutr. $=$ Flavius Eutropius, Breviarium Historiae Romanae, ed. de Santini, C. (1979): Eutropii Breviarium ab urbe condita. Leipzig: Teubner.

Fest. $=$ Sexto Pompeyo Festo, De verborum significatu quae supersunt, ed. de Lindsay, W.M. (1913): Sexti Pompei Festi De verborum significatu quae supersunt cum Pauli epitome. Leipzig: Teubner. 
Flor. Epit. = Lucius Annaeus Florus, Epitome rerum Romanorum, ed. de Malcovati, E. (1972): L. Annaei Flori quae exstant. Roma: Accad. Lynceorum (segunda ed.).

Hirt. Gal. = Aulus Hirtius, De bello gallico, ed. de Hering, W.C. (1997): Gaius Iulius Caesar: Commentarii rerum gestarum: Bellum Gallicum. Leipzig: Stuttgart.

It. Ant. = Itinerarium provinciarum Antonini Augusti, ed. de Cuntz, O. (1929): Itineraria romana 1. Itinerarium Antonini Augusti et Burdigalense. Leipzig: Teubner: 86-102.

Liv. = Titus Livus Patavinus, $A b$ urbe condita, ed. de Mac Donald, A.H. (1969): Titus Livius. Ab urbe condita. Oxford: Oxford University Press (primera ed. de 1964); y Sage, E.T. (1965): Titus Livius. The history of Rome. London-Cambridge (Massachusetts): Harvard University Press.

Not. Gal. $=$ Notitia provinciarum et civitatum Galliae, ed. de Mommsen, T. (1892): Monumenta Germaniae Historica, Auctores antiquissimi, 9.1: 552-612.

Oros. Hist. = Orosius, Historiarum adversum paganos libri VII, ed. de Arnaud-Lindet, M.P. (1991): Orose. Histoires (contre les Paiens). Paris: Les Belles Lettres.

Plb. = Polybius, Historiae, ed. de Pédech, P., de Foucault, J.A. (1990): Polybe, Histoires. Paris: Les Belles Lettres.

Plin. Nat. = Plinius, Naturalis Historia, ed. de Rackham, H. (1942): Natural History. With an English translation. Cambridge (Massachusetts): Harvard University Press.

Ptol. = Ptlolemaios, Geographia, ed. de Siloé, arte y bibliofilia (2006): Cosmografía de Claudio Ptolomeo. Burgos.

Sil. = Silius Italicus, Punica, ed. de Miniconi P., Devallet, G. (1979-1984): Silius Italicus. La Guerre Punique. Tomos I-III. Paris: Les Belles Lettres.

Str. = Strabo, Geographika, ed. de Radt, S. (2009): Strabo, Geographika. Göttingen: Vandenhoeck \& Ruprecht.

Tac. Agr. $=$ Tácito, De vita et moribus Iulii Agricolae, ed. de Ogilvie, R.M., Richmond, I. (1967): De vita Agricolae. Oxford: Clarendon Press. 
Tib. = Albius Tibullus, Elegiae, ed. de della Conte, F. (1997): Tibullo. La elegie. Milano: Fondazione Lorenzo Valla $\left(1^{\text {a }} \mathrm{ed}\right.$. 1980).

V. Max. = Valerius Maximus, Facta et dicta memorabilia, ed. bilingüe de Faranda R. (1988): Valerio Massimo, Detti e fatti memorabili. Milano: Editori Associati.

\section{Bibliografía}

Allen, J. (1999): Hostage-taking and cultural diplomacy in the Roman Empire. Michigan: Ann Arbor.

Allen, J. (2006): Hostages and hostage-taking in the Roman Empire. Cambridge: University of Cambridge.

Álvarez Clavijo, P., Labeaga, J.C., Martínez Clemente, J. (1994): “El yacimiento berón de La Custodia (Viana, Navarra)”, en: J.A. Sesma Muñoz (coord.), Historia de la ciudad de Logroño, Vol. 1. Zaragoza: Ibercaja y Ayuntamiento de Logroño: 65-69.

Álvarez Pérez-Sostoa, D. (2009): Los rehenes en la República Romana: función social, política e ideológica (264-31). Tesis Doctoral. Vitoria-Gasteiz: Universidad del País Vasco - Euskal Herriko Unibertsitatea.

Amela, L. (2011): "Cn Domicio Calvino y los cerretanos". Hispania Antiqua, 35: 43-65.

Andreu, J. (2006): "Ciudad y territorio en el solar de los «Vascones» en época romana”, en: J. Andreu (coord.), Navarra en la Antigüedad. Propuesta de actualización. Pamplona: Gobierno de Navarra: 179-228.

Armendáriz, J. (1997-1998): "El yacimiento arqueológico de La Custodia (Viana): triste trayectoria de una ciudad berona excepcional". Trabajos de Arqueología Navarra, 13: 7-33.

Armendáriz, J. (2008): De aldeas a ciudades: el poblamiento durante el primer milenio a.C. en Navarra. Pamplona: Gobierno de Navarra.

Armendáriz, J. (2009): "La ordenación del territorio vascón en la Edad del Hierro", en: J. Andreu (ed.), Los Vascones en las Fuentes Antiguas: en torno a una etnia de la Antigüedad Peninsular. Barcelona: Universitat de Barcelona: 303-338. 
Armendáriz, J. (2013): "Siglo y medio de investigaciones: estado actual de la arqueología de época antigua en Navarra". Cuadernos de Arqueología de la Universidad de Navarra, 21: 151-218.

Balbín, P. (2006): Hospitalidad y patronato en la Península Ibérica durante la Antigüedad. Salamanca: Junta de Castilla y León.

Bedon, R. (2003): "Les agglomérations indigènes de la péninsule ibérique chez Tite-Live". Gerión, 21.1: 229-263.

Beltrán, F. (2001): "Hacia un replanteamiento del mapa cultural y étnico del norte de Aragón”, en: F. Villar, M.P. Fernández (coord.), Religión, lengua y cultura prerromanas de Hispania. Salamanca: Universidad de Salamanca: 61-82.

Beltrán, F. (2010): “El hospitium celtibérico", en: F. Burillo (ed.), Ritos y mitos. VI Simposio sobre Celtíberos. Daroca: Fundación Segeda - Centro de Estudios Celtibéricos: 273-289.

Blázquez, J.M. (1996): España romana. Madrid: Cátedra.

Bosch Gimpera, P. (1932): “Los celtas y el País Vasco”. Revista Internacional de Estudios Vascos, 23.3: 457-486.

Bost, J.P. (1986): "P. Crassum... in Aquitaniam proficisci iubet: Les chemins de Crassus en 56 avant Jésus-Christ”. Hommage à Robert Étienne, Revue des Études Anciennes, 88.1-4: 21-39.

Brizzi, G. (2007): Escipión y Aníbal. La guerra para salvar Roma. Madrid: Ariel.

Canto A. (1997): "La tierra del toro: ensayo e identificación de ciudades vasconas". Archivo Español de Arqueología, 70.175-176: 31-70.

Cantón Serrano, E. (2003): Los vascones entre el Ebro y Aquitania: la organización social. Tesis Doctoral, Vitoria-Gasteiz: Universidad del País Vasco - Euskal Herriko Unibertsitatea.

Cantón Serrano, E. (2005): "Sobre la expansión vascona en las fuentes literarias". Veleia, 22: 129-144.

Ciprés, P. (2002): "Instituciones militares indoeuropeas en la Península Ibérica”, en: P. Moret, F. Quesada (coord.), La guerra en el mundo ibérico y celtibérico (ss. VI-II a. de C.): Seminario celebrado en la Casa de Velázquez (marzo de 1996). Madrid: Casa de Velázquez: 135-152.

Castiella, A. (2003): Por los caminos romanos de Navarra. Pamplona, Caja Navarra. 
Clémens, J. (1981): “Aux origines d’une région historique: Ténarèze et Peyrigne en Agenais". Annales du Midi, 93: 83-90.

Collado Cenzano, L.V. (2006): "La identidad de los berones bajo la romanización”. Berceo, 150: 91-114.

Desjardins, E. (1878): Géographie historique et administrative de la Gaule Romaine, T. II. Paris.

Deyver, A. (2009): Les Gaulois en guerre. Stratégies, tactiques et techniques. Paris: Editions Errance.

Díaz Sanz, M.A., Jordán, C.B. (2006): “Dos téseras de hospitalidad procedentes de Fitero (Navarra)". Palaeohispánica, 6: 257-262.

Dopico, M.D. (1998): “La devotio ibérica: una revisión crítica”, en: J. Mangas, J. Alvar (coord.), Homenaje a José María Blázquez: de Oriente a Occidente, Vol. 2. Madrid: Universidad Complutense de Madrid, Ediciones Clásicas: 181-194.

Emborujo, A., Ortiz de Urbina, E., Santos, J. (1992): “Reconstrucción paleogeográfica de autrigones, caristios y várdulos”. Complutum, 2-3: 449-468.

Elbern, S. (1987): “Das Goten massaker in kleinasien”. Hermes, 115.1: 99-106.

Espinosa Ruiz, U. (1990): Vareia, enclave romano en el valle del Ebro. Alicante: Biblioteca Virtual Miguel de Cervantes.

Espinosa Ruiz, U. (1994a): "Ordenación territorial republicana, novedades", en: J.A. Sesma Muñoz (coord.), Historia de la ciudad de Logroño, Vol. 1. Zaragoza: Ibercaja y Ayuntamiento de Logroño: 106-108.

Espinosa Ruiz, U. (1994b): “Roma conquista el medio Ebro", en: J.A. Sesma Muñoz (coord.), Historia de la ciudad de Logroño, Vol. 1. Zaragoza: Ibercaja y Ayuntamiento de Logroño: 99-103.

Fatás, G. (1971): “Sobre Suessetanos y Sedetanos”. Archivo Español de Arqueología, 44: 109-125.

Fatás, G. (1975): "Hispania entre Catón y Graco: algunas precisiones basadas en las fuentes". Hispania Antiqua, 5: 269-313.

Fatás, G. (1992): "Para una etnogeografía de la Cuenca Media del Ebro". Complutum, 2-3: 223-232.

Fatás, G. (1993): "Los Pirineos meridionales y la conquista romana”, en: F. Villar, J. Untermann (coords.), Lengua y cultura en Hispania prerromana: actas del V Coloquio sobre lenguas 
y culturas de la Península Ibérica: (Colonia 25-28 de Noviembre de 1989), Acta Salmanticensia. Estudios Filológicos, 251: 289-316.

García Mora, F. (1991): Un episodio de la Hispania republicana: la guerra de Sertorio. Granada: Universidad de Granada.

García Mora, F. (1992): "Las primeras repercusiones del conflicto Sertoriano en tierras vasconas". Príncipe de Viana, Anejo, 14: 207-216.

García Riaza, E. (1997): "La función de los rehenes en la diplomacia hispano-republicana". Memorias de Historia Antigua, 18: 81-108.

García Riaza, E. (1998-1999): “Derecho de guerra romano en Hispania (218-205 a.C.)". Memorias de Historia Antigua, 19-20: 199-224.

García Riaza, E. (2002): Celtíberos y lusitanos frente a Roma: diplomacia y derecho de guerra. Vitoria-Gasteiz: Universidad del País Vasco-Euskal Herriko Unibertsitatea.

García Riaza, E. (2005): "En torno a la paz de Graco en Celtiberia", en: J. Alvar Ezquerra (coord.), Actas del IX Congreso Español de Estudios Clásicos, 1. Madrid: Sociedad Española de Estudios Clásicos y Ediciones Clásicas: 469-480.

García Riaza, E. (2007): “Tempus poenae: represalias contra poblaciones sometidas durante la expansión romana en Hispania”, en: G. Bravo, R. González (coord.), Formas y usos de la violencia en el mundo romano. Madrid: Signifer Libros: 19-30.

García Riaza, E. (2010): “Contactos diplomáticos entre civitates galas durante la intervención cesariana”, en: L. Lamoine et al. (dir.), La praxis municipale dans l'Occident romaine. Clermont-Ferrand: Collection Histoires Croisées: 143-156.

García Riaza, E. (2013): “Alianzas regionales e identidad supralocal en Occidente durante la etapa de expansión romana (ss. III-I a.C.)", en: S. Lefebvre (coord.), Identités et dynamiques provinciales du IIe siècle avant notre ère à l'époque julio-claudienne. Dijon: Éditions Universitaires de Dijon: 13-27.

Gardes P. (2001): "Habitat, territoires et évolution sociale en Aquitaine durant le dernier millénaire av. J.-C.”, en: L. Berrocal, P. Gardes (eds.), Entre celtas e íberos: las poblaciones 
protohistóricas de las Galias e Hispania. Madrid: Casa de Velázquez: 115-135.

Gorrochategui Churruca, J. (1990): “Consideraciones sobre la fórmula onomástica y la expresión del origen en algunos textos celtibéricos menores", en: F. Villar (ed.), Studia indogermanica et palaeohispanica in honorem A. Tovar et L. Michelena. Vitoria-Salamanca: Universidad del País Vasco - Universidad de Salamanca: 291-312.

Hernández Vera, J.A. (2002): "La fundación de Graccurris", en: A. Ribera i Lacomba, J. Jiménez Salvador (coord.), Valencia y las primeras ciudades romanas de Hispania. Valencia: Ajuntament de Valencia: 173-182.

Jordán Cólera, C.B. (1997): “A propósito de las téseras celtibéricas de Viana”. Kalathos, 16: 199-211.

Jordán Cólera, C.B. (1998): Introducción al celtibérico. Zaragoza: Universidad de Zaragoza.

Konrad, C.F. (1990): "Metellus and the head of Sertorius". Hispania Antiqua, 14: 33-40.

Labeaga, J.C. (1987): "Amuletos mágicos y téseras de hospitalidad en los yacimientos arqueológicos de Viana". Príncipe de Viana, 2: 453-463.

Labeaga, J.C. (1999-2000): "Los berones, Vareia y el poblado de La Custodia”. Trabajos de Arqueología Navarra, 14: 205-224.

Labeaga, J.C., Untermann, J. (1993-1994): “Las téseras del poblado prerromano de la Custodia, Viana (Navarra). Descripción, epigrafía y lingüística". Trabajos de Arqueología Navarra, 11: 45-53.

Lanz, J. (2016a): “A propósito de una legatio en el «Ara de Hasparren»", en: R. Cordeiro, A. Vázquez (ed.), Estudos de Arqueoloxía, Prehistoria e Historia Antiga: achega dos novos investigadores. Santiago de Compostela: Andavira: 537-552.

Lanz, J. (2016b): “Antzinateko baskoiak: izen eta izanaren arteko eztabaidak (XVI.-XXI. mendeak)”. Sancho el Sabio, 39:33-65.

Larrañaga, K. (2007): El hecho colonial romano en el área circumpirenaica occidental. Vitoria-Gasteiz: Universidad del País Vasco - Euskal Herriko Unibertsitatea. 
Larrieu-Duler, M. (1972): "Les origines de Lectoure", en: M. Bordes et al., Histoire de Lectoure. Auch: Bouquet: 10-36.

Lee, A.D. (1991): "The role of hostages in roman diplomacy with Sasanian Persia". Historia: Zeitschrift für Alte Geschichte, 40.3: 366-374.

López Melero, R. (1987): “Gracchurris fundación celtibérica?”. Veleia, 4: 171-177.

Martínez Morcillo, J.A. (2014): "Las coaliciones antirromanas en Galia Cisalpina y su sometimiento a Roma (225-191 a.C.)”, en: G. Bravo, R. González (coord.), Conquistadores y conquistados: relaciones de dominio en el mundo romano. Actas del XI Coloquio de la Asociación Interdisciplinar de Estudios Romanos. Salamanca: Signifer Libros: 339-356.

Maurin, L. (1971): “Les Basaboiates”. Cahiers du Bazadais, 20-21: 1-15.

Medrano, M., Díaz, M.A. (2003): "El patrimonio arqueológico de Fitero (Navarra)”. Salduie, 3: 395-405.

Moret, P. (1997): "Les Ilergètes et leurs voisins dans la troisième décade de Tite Live”. Pallas, 46: 147-165.

Muñiz Coello, J. (1994): "Instituciones políticas celtas e ibéricas, un análisis de las fuentes literarias”. Habis, 25: 91-105.

Muñiz Coello, J. (1995): “Guerra y paz en la España céltica: clientes y hospites a la luz de las fuentes literarias". Hispania Antiqua, 19: 15-36.

Nörr, D. (1996): La fides en el derecho internacional romano. Madrid: Fundación Seminario de Derecho Romano Ursicino Álvarez.

Olcoz, S., Medrano, M. (2008): “Revisión paleogeográfica de las inscripciones celtibéricas en signario paleohispánico". Espacio, tiempo y forma. Serie II, Historia Antigua: 105-122.

Olcoz, S., Medrano, M. (2011): “Una tésera de hospitalidad procedente de Cascante (Navarra)". Veleia, 28: 245-252.

Pamplona, G. (1996): "Los límites de la Vasconia hispano-romana y sus variaciones en época imperial”, en: IV Simposio de Prehistoria Peninsular. Pamplona: Diputación Foral de Navarra: 207-222. 
Peñalver, X. (2008): La Edad del Hierro. Los vascones y sus vecinos. El último milenio anterior a nuestra era. Donostia: Txertoa.

Peralta Labrador, E. (2000): Los cántabros antes de Roma. Madrid: Real Academia de la Historia.

Pérex Agorreta, M.J. (1986): Los Vascones (el poblamiento en época romana). Pamplona: Gobierno de Navarra.

Pérez Rubio, A. (2011): Alianzas y coaliciones en la Hispania prerromana. Trabajo Fin de Master, Madrid: Universidad Autónoma de Madrid.

Pérez Rubio, A. (2014): "Coaliciones en el mundo celtibérico", en: F. Burillo, M. Chordá (ed.), VII Simposio sobre celtíberos. Nuevos hallazgos, nuevas interpretaciones. Teruel: Centro Estudios Celtibéricos Segeda: 161-175.

Pérez Rubio, A., Sánchez Moreno E., Per Gimeno L., Martínez Morcillo J.A., García Riaza E. (2013): "Symmachíai celtibéricas (220-133 a.C.): coaliciones militares en el horizonte del imperialismo mediterráneo”. Palehoispánica, 13: 675-697.

Pina Polo, F. (2006): "Calagurris contra Roma: de Acidinio a Sertorio”. Kalakorikos, 11: 117-129.

Prieto Arciniega, A. (1978): "La devotio ibérica como forma de dependencia en la Hispania prerromana". Memorias de Historia Antigua, 2: 13-135.

Ramos Loscertales, J.M. (1924): "La devotio ibérica”. Anuario de Historia del Derecho Español, 1: 7-26.

Ramírez Sádaba, J.L. (2002): "Navarra: los colectivos sociales en la Antigüedad". en: V. Congreso de Historia de Navarra. Grupos sociales en Navarra. Relaciones y derechos a lo largo de la historia, Vol. 3. Pamplona: Gobierno de Navarra: 21-56.

Ramírez Sádaba, J.L. (2009): "La toponimia de las ciudades vasconas", en: J. Andreu (coord.), Los Vascones en las Fuentes Antiguas: en torno a una etnia de la Antigüedad Peninsular. Barcelona: Universitat de Barcelona: 127-146.

Rivero Gracia, M.P. (2002): "La campaña militar de Domicio Calvino en el 39 a.C. y la ubicación de los cerretanos", en: L. Hernández et al. (eds.), Actas del I Congreso Internacional de Historia Antigua "La Península Ibérica hace 2000 años", 
Valladolid 23-25 de noviembre de 2000. Valladolid: Universidad de Valladolid: 59-163.

Salinas de Frías, M. (1995): El gobierno de las provincias hispanas durante la República romana (218-27 a.C.). Salamanca: Universidad de Salamanca.

Santos, J. (2006): "Los pueblos del País Vasco en las fuentes antiguas”, en: P. Barruso, J.A. Lema (coord.) Historia del País Vasco. Prehistoria y Antigüedad. Donostia: Hiria: 171-193.

Sayas, J.J. (1992): “El territorio aquitano entre la asimilación romana y el mantenimiento de su especificidad". Segundo Congreso General de Historia Navarra, 2, Conferencias y comunicaciones sobre Prehistoria, Historia Antigua e Historia Medieval, Príncipe de Viana, Anejo, 14.53: 153-180.

Sayas, J.J. (1994): Los Vascos en la Antigüedad. Madrid: Cátedra.

Schulten, A. (1927): "Las referencias sobre los Vascones hasta el año 810 después de J.C." Revista Internacional de Estudios Vascos, 18.2: 225-240.

Simón, I. (2008): “Cartografía de la epigrafía paleohispánica I. Las téseras de hospitalidad”. Palaeohispánica, 8: 127-142.

Untermann, J. (1995): “Testimonios de lengua prerromana en territorio riojano", en: Historia de la ciudad de Logroño. Zaragoza: Ayuntamiento de Logroño - Ibercaja, Zaragoza: 81-87.

Velaza Frías, J. (1989): “A propósito de las téseras de hospitalidad de Viana”. Veleia, 6: 193-197. 